\title{
A nomogram for endoscopic screening in a high esophageal squamous cell cancer risk area: results from a population-based study
}

This article was published in the following Dove Press journal:

Cancer Management and Research

Jie Xing,' Li Min,' Hao Zhang, ${ }^{2}$ Peng Li,' Wei Li,' Fujin Lv,' Yongjun Wang,' Zheng Zhang,' Hengcun Li,' Qingdong Guo,' Siyi Wang,' Yu Zhao,' Junmin Wang, ${ }^{3}$ Xiaoyan Shi, ${ }^{4}$ Anxin Wang, ${ }^{5}$ Shengtao Zhu,' Ming Ji,' Yongdong Wu,' Shutian Zhang'

\section{On behalf of the NCECS Study Group}

'Department of Gastroenterology, Beijing Friendship Hospital, Capital Medical University, National Clinical Research Center for Digestive Disease, Beijing Digestive Disease Center, Beijing Key Laboratory for Precancerous Lesion of Digestive Disease, Beijing I00050, People's Republic of China; ${ }^{2}$ Department of Gastroenterology, Jizhong Energy Fengfeng Group Hospital, Handan, Hebei 056200, People's Republic of China; ${ }^{3}$ Department of Gastroenterology, Handan Central Hospital, Handan, Hebei 05600I, People's Republic of China; ${ }^{4}$ Department of Pathology, Beijing Friendship Hospital, Capital Medical University, Beijing 100050 People's Republic of China; ${ }^{5}$ Department of Epidemiology, Beijing Tiantan Hospital, Capital Medical University, Beijing 100029 , People's Republic of China
Correspondence: Shutian Zhang Department of Gastroenterology, Beijing Friendship Hospital, Capital Medical University, National Clinical Research Center for Digestive Disease, Beijing Digestive Disease Center, Beijing Key Laboratory for Precancerous Lesion of Digestive Disease, 95 Yongan Road, Beijing 100050, People's Republic of China

Email zhangshutian@ccmu.edu.cn
Background: Endoscopy is the main approach used for esophageal squamous cell carcinoma (ESCC) screening, especially in high-risk areas. However, little consensus has been achieved in recent ESCC screening programs, and endoscopists have selected patients only by age and family history.

Patients and methods: To generate a proper strategy for selecting an eligible population for endoscopic screening based on demographic factors, lifestyle, and eating habits, a total of 7,830 residents in an area with a high risk of ESCC were recruited for this study. All participants underwent endoscopic examinations that were conducted by experienced endoscopists. Risk factors for ESCC and other lesions were selected by univariate and multivariate logistic regressions. A nomogram for the prediction of ESCC and premalignant lesions was constructed, which included information on age, sex, occupation, labor intensity, income, and mining exposure. Receiver operating characteristic (ROC) curve analysis was performed to present the predictive accuracy of the nomograms. Results: The area under the curve $(95 \%$ CI) was $0.749(0.711-0.788)$ for this nomogram. By applying this nomogram, we could exclude 60\% (4704/7830) of patients before endoscopy screening and detect all ESCC cases as well as most esophageal lesions in the remaining population.

Conclusion: In conclusion, we provided a ready-to-use preclinical tool with the potential to select eligible people with high risk of ESCC for endoscopy screening.

Keywords: nomogram, endoscopy screening, ESCC, population-based study

\section{Introduction}

With a total of 4,56,000 new cases and nearly 4,00,000 deaths in 2012, esophageal cancer (EC) ranks as the eighth most common malignant carcinoma and the sixth leading cause of death worldwide. ${ }^{1}$ Esophageal adenocarcinoma (EAC) is the main subtype of EC in western countries, and its incidence has increased dramatically in the past decades. ${ }^{2}$ However, esophageal squamous cell carcinoma (ESCC) remains the dominatant subtype in East Asia. ${ }^{3}$ Though ESCC has steadily decreased along with various socioeconomic developments and changes in lifestyle, it remains the greatest cancer burden in some high-risk areas. ${ }^{3}$

Due to deficiencies in the serous layer, ESCC is highly aggressive and easily invades neighboring tissues. ${ }^{4}$ Most ESCC patients are diagnosed at a late stage and have a very poor prognosis. ${ }^{5}$ Kumar et al reported that the overall 5-year survival of ESCC is only $9 \%$, but with early detection and treatment, the survival rate increases significantly. ${ }^{6}$ Morimoto et al from Japan reported that the 5-year survival rates decreased dramatically if there had been a failure to diagnose the disease at a very early stage, ie, the 5-year survival rates for stage 0 ESCC was $83 \%$ but only $47 \%$ for 
stage I ESCC. ${ }^{7}$ Increasing the early detection rate of ESCC would be very beneficial for reducing the medical burden of high ESCC risk areas. ${ }^{8}$

Recently, for EAC, premalignant and precursor lesions have been well studied. Risk factors such as esophagitis, gastroesophageal reflux diseases, Barrett esophagus, drinking, and smoking are widely recognized and discussed in EAC screening guidelines. ${ }^{9}$ However, for ESCC, many risk factors have been proposed, such as age, sex, smoking, and drinking, but little consensus has been reached. ${ }^{10,11}$ Due to the lack of clinical and epidemiological evidence to select eligible people with high risk, ESCC screening has been nearly totally dependent on endoscopy. ${ }^{9}$ Recently, ESCC screening programs selected patients only by age and family history, ${ }^{12-14}$ which resulted in low compliance in screening and wasted medical resources.

In this study, we established a cohort undergoing endoscopic screening in Handan City, Hebei province (located in the Taihang Mountain area, a famous high ESCC risk area in People's Republic of China), to investigate the independent risk factors of ESCC and to establish a method to select the eligible population for endoscopic screening based on demographic data, lifestyle factors, eating habits, and psychological factors.

\section{Patients and methods Study population and inclusion/exclusion criteria}

The study was approved by Medical Ethics Committee of Beijing Friendship Hospital, Capital Medical University in compliance with the Declaration of Helsinki. A total of 10,135 residents between 40 and 70 years old in Handan City, Hebei Province (where the incidence of ESCC is higher than in other regions of People's Republic of China) were recruited during October 2010 to September 2011 for this study. Written informed consent was obtained from 8,040 residents, and 8,027 finished the epidemiology questionnaire. General health examinations were performed, and 197 people with iodine allergy, any other tumors, hyperthyreosis, pregnancy, lactation, and psychosis were excluded. After questionnaire administration and physical examination, a total of 7,830 participants were enrolled and successfully completed an upper gastrointestinal endoscopy examination (Figure 1).

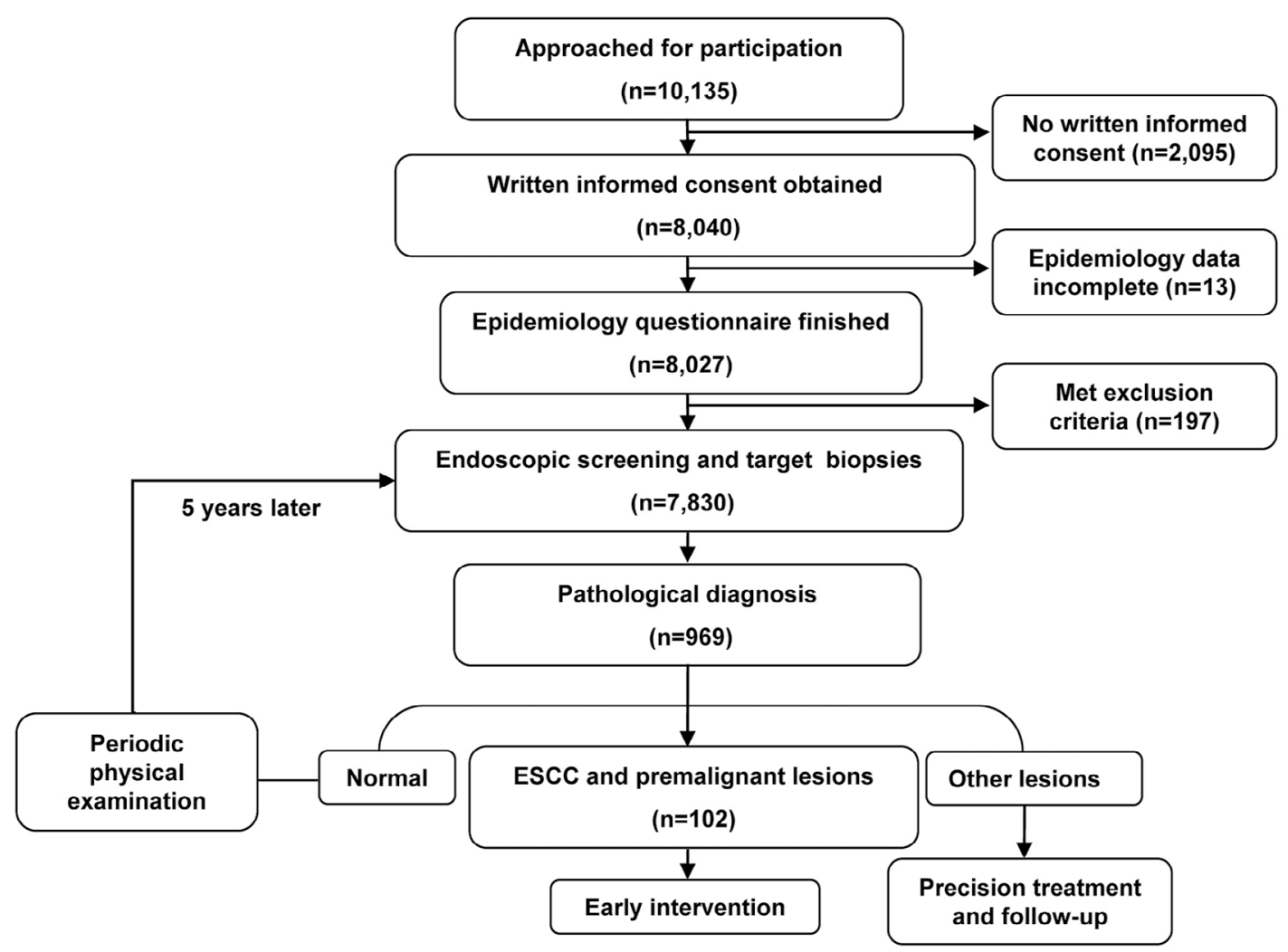

Figure I Flowchart of participant inclusion and exclusion.

Notes: A total of 10,135 residents were recruited in this study. Of these, 8,040 residents provided written informed consent and 8,027 completed the epidemiology questionnaire. Then, 197 people were excluded due to the exclusion criteria (iodine allergy, hyperthyreosis, pregnancy, etc.). Finally, 7,830 participants were enrolled and successfully completed an upper gastrointestinal endoscopy examination. 


\section{Endoscopy performance and quality control}

All of the endoscopic examinations and therapies were completed by experienced endoscopists of the National Clinical Research Center for Digestive Disease. Fasting for at least 8 hours was required, and anticoagulant drugs were to be stopped 1 week before endoscopy. Iodine staining was applied to facilitate the discovery of lesions. Any esophageal lesions including carcinoma, dysplasia, hyperplasia, inflammatory lesions, ulcers, and reflux esophagitis were biopsied, and 5\% of normal esophageal mucosa were also examined as negative controls. Each specimen of biopsied tissue was examined by two pathologists using the World Health Organization 2010 digestive oncopathologic diagnostic criteria (representative pathological and endoscopic images are displayed in Figure 2).

\section{Data acquisition and processing}

Questionnaires were mailed to participants to collect data regarding demographics, lifestyle factors, eating habits, psychological factors, etc. Smoking status was divided into four subgroups: yes (smoking $>6$ months and $\geq 1$ cigarettes per day), occasionally (smoking $<1$ cigarette/day or $<6$ months), refrained (ie, stopped smoking for $>6$ months), and never (never smoked). Eating habits (including leek food intake, fresh vegetable consumption, etc.) was defined by two subgroups: yes ( $\geq 3$ times per month) and rarely or never (never or $<3$ times per month). Endoscopic examinations were performed to collect data on different esophageal diseases including reflux esophagitis, dysplasia, ulcers, etc. The data regarding pathological diagnoses were based on the consensus of two pathologists. All questionnaires and clinical information were entered into the database "back to back" by two researchers independently.

\section{Statistical analyses}

All statistical analyses were performed using R Software 3.2.2 (www.r-project.org). Packages "plyr", "dplyr", and "reshape2" were loaded for data cleaning, and package "rms"
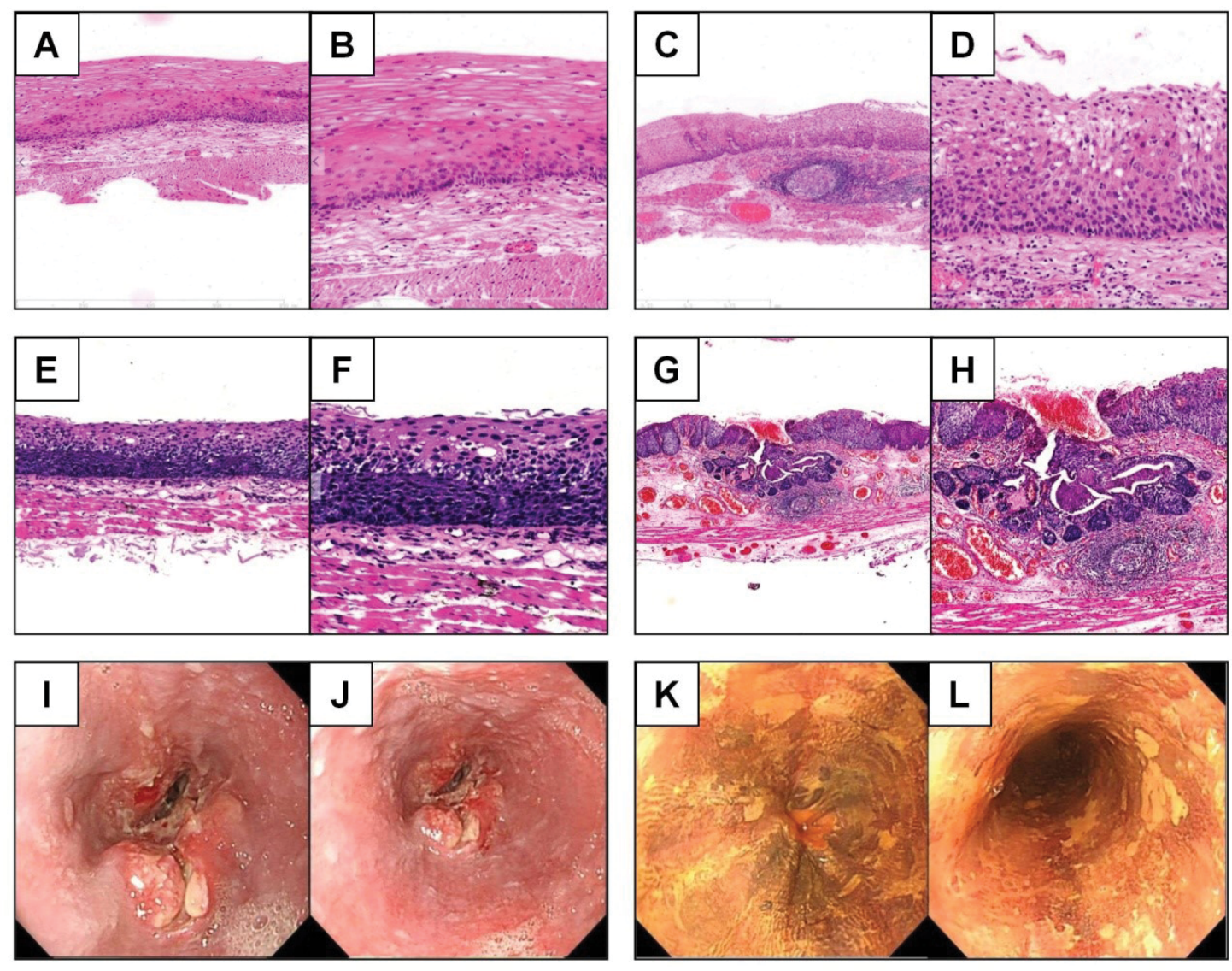

Figure 2 Representative immunological and endoscopic images of different esophageal diseases.

Notes: Representative immunohistochemical images of esophageal low-grade dysplasia (A. 20×, B. 40×), esophageal middle-grade dysplasia (C. 20×, D. 40×), esophageal high-grade dysplasia (E. 20x, F. 40x), and ESCC (G. 20×, H. 40×). Representative endoscopic images of uneven surface of the esophagus (I, J) and an iodine-unstained area in the esophageal mucosa $(\mathbf{K}, \mathbf{L})$.

Abbreviation: ESCC, esophageal squamous cell carcinoma. 
was used for nomogram building. Univariate analysis was performed to identify risk factors for esophageal lesions, and an OR with $95 \%$ CI of potential risk factors was displayed. Then, multivariate regression analysis was used to select independent influence factors, and nomograms were built based mainly on these results. A receiver operating characteristic (ROC) curve was used to present the predictive accuracy of nomograms graphically. The area under the curve (AUC) for validation was applied to evaluate the accuracy of the nomograms. We performed calibration for the established nomograms and applied 1,000 repetitions of bootstrap sample corrections to internally validate the nomograms. All statistical results with $P<0.05$ were regarded as statistically significant.

\section{Results \\ Descriptive analysis of the patient population}

Overall, 7,830 patients successfully completed an upper gastrointestinal endoscopy examination, and detailed data on demographics, lifestyle factors, eating habits, occupational factors, and disease history were collected. The most common esophageal lesions represented in this population were reflux esophagitis $(15.22 \%, \mathrm{n}=1,193)$, inflammatory lesions $(5.68 \%, \mathrm{n}=445)$, and dysplasia $(1.25 \%, \mathrm{n}=98)$. Only four carcinomas were detected $(0.05 \%)$, and all of them were ESCC. There were 14 cases of hyperplasia $(0.18 \%) ; 10$ cases of esophageal ulcer $(0.13 \%)$ were also represented (Table 1 ).

Based on the consensus of the participating local physicians and endoscopists of National Clinical Research Center for Digestive Disease, it was suggested that given the available data (low detection rates of carcinoma and dysplasia), a nomogram to predict carcinoma and premalignant lesions (dysplasia) risk would be very helpful in shrinking the population eligible for endoscopy screening.

\section{Detect risk factors for ESCC and premalignant lesions}

To generate a nomogram for the prediction of ESCC and premalignant lesions, we summarized the univariate logistic regression analyses of ESCC/premalignant lesions (Table 2 and Table S1). Age, sex, education, occupation, labor intensity, income, mining exposure, hypertension, and tea consumption were all associated with ESCC and premalignant lesions risk (all $P<0.05$ ). However, in the multivariate analysis, only age, sex, and occupation were
Table I Esophageal lesions in 7,830 cases

\begin{tabular}{lll}
\hline Lesions & Number & Percentage \\
\hline Carcinoma & 4 & 0.05 \\
Dysplasia & 98 & 1.25 \\
Hyperplasia & 14 & 0.18 \\
Inflammatory lesions & 445 & 5.68 \\
Esophageal ulcer & 10 & 0.13 \\
Reflux esophagitis & 1,193 & 15.24 \\
Normal esophagus & 6,066 & 77.47 \\
\hline
\end{tabular}

independent predictive factors for ESCC/premalignant lesions (Table 2). Older people had a higher probability of ESCC/premalignant lesions compared with younger ones $(P<0.001)$. Men had a higher risk than women $(P=0.010)$. Officers and peasants had a higher risk than people with other occupations $(P=0.012)$. Other esophageal lesions were also investigated. Age, sex, education, smoking, smoking exposure, drinking, mining exposure, dust exposure, gas exposure, foreign residency, and tea consumption were all associated with esophageal precursor lesions, while age, sex, occupation, labor intensity, income, smoking, smoking time, smoking exposure, drinking, mining exposure, mining exposure time, dust exposure, gas exposure, hypertension, diabetes, disease history, fried food consumption, fresh fruit consumption, and tea consumption were all associated with reflux esophagitis (Table 3 ).

\section{A nomogram for the prediction of ESCC and premalignant lesions}

We used the independent ESCC risk factors (age, sex, and occupation) to develop a predictive nomogram for the general population eligible for endoscopy screening. Three additional factors (labor intensity, income, mining exposure) were also included, considering their corresponding OR value in univariate analysis. Half of the cases were sampled by the Monte Carlo method, and a predictive nomogram was generated, which is shown in Figure 3A. For each patient, points were assigned for each of these demographic and medical factors (age, sex, education, occupation, labor intensity, income, and mining exposure), then a total score and a corresponding prediction of the probability of ESCC/ premalignant lesions were calculated from the nomogram. An ROC curve was drawn to estimate the predictive accuracy of the nomogram, and the AUC $(95 \% \mathrm{CI})$ was 0.749 (0.711-0.788; Figure 3B). The other half of the cases were used for validation, and the AUC $(95 \% \mathrm{CI})$ was 0.742 (0.704-0.780) for the validation cohort, indicating a very good concordance (Figure 3C). A calibration curve gener- 
Table 2 Univariate and multivariate analyses of risk factors for ESCC and premalignant lesions

\begin{tabular}{|c|c|c|c|c|c|c|}
\hline & \multicolumn{3}{|c|}{ Univariate $^{a}$} & \multicolumn{3}{|c|}{ Multivariate } \\
\hline & OR & $95 \% \mathrm{Cl}$ & $P$ & OR & $95 \% \mathrm{Cl}$ & $P$ \\
\hline Age (years) & & & $<0.001$ & & & $<0.00$ I \\
\hline $4 \mathrm{I}-50$ vs $\leq 40$ & 1.06 & $(0.38,4.44)$ & & 0.93 & $(0.33,3.94)$ & \\
\hline $5 \mathrm{I}-60$ vs $\leq 40$ & 3.76 & $(1.38,15.48)$ & & 2.21 & $(0.78,9.26)$ & \\
\hline$>60$ vs $\leq 40$ & 10.87 & $(3.61,46.90)$ & & 3.88 & $(1.09,18.50)$ & \\
\hline Sex & & & 0.009 & & & 0.010 \\
\hline Female vs Male & 0.54 & $(0.32,0.86)$ & & 0.62 & $(0.50,0.79)$ & \\
\hline Education & & & $<0.001$ & & & \\
\hline High school vs College & 1.15 & $(0.59,2.46)$ & & & & \\
\hline Middle school vs College & 0.91 & $(0.47,1.94)$ & & & & \\
\hline Primary school vs College & 3.37 & $(1.58,7.60)$ & & & & \\
\hline Occupation & & & $<0.001$ & & & 0.012 \\
\hline Peasant vs Worker & 3.15 & $(0.76,8.77)$ & & 1.98 & $(0.43,6.44)$ & \\
\hline Officer vs Worker & 2.34 & $(1.37,3.86)$ & & 2.86 & $(1.38,5.75)$ & \\
\hline Service vs Worker & 0.44 & $(0.02,2.01)$ & & 0.67 & $(0.04,3.32)$ & \\
\hline Retired vs Worker & 4.76 & $(2.92,7.6 I)$ & & 2.10 & $(1.02,4.26)$ & \\
\hline Others vs Worker & 1.09 & $(0.06,5.07)$ & & 0.73 & $(0.04,4.01)$ & \\
\hline Labor intensity & & & 0.006 & & & \\
\hline Moderate vs Light & 0.59 & $(0.37,0.91)$ & & & & \\
\hline Heavy vs Light & 0.39 & $(0.16,0.80)$ & & & & \\
\hline Income (¥) & & & 0.008 & & & \\
\hline $2,00 \mathrm{I}-3,000$ vs $\leq 2,000$ & 0.52 & $(0.32,0.84)$ & & & & \\
\hline $3,00 \mathrm{I}-4,000$ vs $\leq 2,000$ & 0.44 & $(0.24,0.76)$ & & & & \\
\hline$>4,000$ vs $\leq 2,000$ & 0.47 & $(0.25,0.84)$ & & & & \\
\hline Mining exposure & & & 0.033 & & & \\
\hline Yes vs No & 1.53 & $(1.04,2.29)$ & & & & \\
\hline Hypertension & & & 0.033 & & & \\
\hline No vs Yes & 0.63 & $(0.42,0.96)$ & & & & \\
\hline Tea consumption & & & 0.038 & & & \\
\hline No vs Yes & 0.60 & $(0.39,0.97)$ & & & & \\
\hline
\end{tabular}

Note: aPartial results of univariate analysis of ESCC and premalignant lesions risk factors; the complete results are found in Table SI. Abbreviation: ESCC, esophageal squamous cell carcinoma.

ated by 1,000 repetitions of bootstrap sample corrections is also illustrated in Figure 3D.

\section{Selecting eligible people for endoscopy screening}

To shrink the population eligible for endoscopy screening in the high ESCC risk area, we assigned a risk score for ESCC and premalignant lesions to each participant in this study according to the nomogram. A $40 \%$ percentile cutoff was applied, and 3,126 out of 7,830 people were identified as at high risk. All ESCC patients (4/4) and three-quarters of patients with premalignant lesions (70/98) were successfully selected in this patient selection strategy (Table 4). Among the remaining 3,052 patients identified as the high-risk group, 784 also had other esophageal diseases (precursor lesions and reflux esophagitis). In the 4,704 people in the low-risk subgroup, 3,962 participants were completely healthy (84.2\%), and no ESCC patients were misdiagnosed.

\section{Discussion}

Many independent cohort studies have indicated that screening of early ESCC could reduce its mortality, and the detection of precancerous lesions likewise has led to a reduction in the incidence of ESCC. ${ }^{12,15}$ However, there are no global or nationwide recommendations for ESCC screening.

Recently, most ESCC screening programs were conducted in the target population defined by several risk factors such as age and family history. ${ }^{12,14}$ Inefficient preselection of eligible people to include resulted in low cost-efficiency in ESCC screening programs. ${ }^{16,17}$ Endoscopic screening with a low true positive rate also caused poor compliance in the target population, according to our experience. A predictive model that provided improved individual risk assessment would facilitate people's decision-making on whether to accept an endoscopy examination.

In this study, age was associated with ESCC/premalignant lesions, precursor lesions, and reflux esophagitis. It is reason- 
Table 3 Univariate analysis of risk factors for benign esophageal lesions

\begin{tabular}{|c|c|c|c|c|c|c|}
\hline & \multicolumn{3}{|c|}{ Precursor lesions } & \multicolumn{3}{|c|}{ Reflux esophagitis } \\
\hline & OR & $95 \% \mathrm{Cl}$ & $P$ & OR & $95 \% \mathrm{Cl}$ & $P$ \\
\hline Age (years) & & & $<0.001$ & & & 0.002 \\
\hline $4 \mathrm{I}-50$ vs $\leq 40$ & 1.59 & $(0.98,2.78)$ & & 1.24 & $(0.94,1.66)$ & \\
\hline $5 \mathrm{I}-60$ vs $\leq 40$ & 2.42 & $(1.48,4.23)$ & & 1.52 & $(1.14,2.05)$ & \\
\hline$>60$ vs $\leq 40$ & 3.36 & $(1.80,6.46)$ & & 1.56 & $(1.03,2.34)$ & \\
\hline Sex & & & $<0.001$ & & & $<0.001$ \\
\hline Female vs Male & 0.62 & $(0.50,0.79)$ & & 0.23 & $(0.19,0.28)$ & \\
\hline Education & & & 0.002 & & & 0.489 \\
\hline High school vs College & 1.69 & $(1.18,2.49)$ & & 0.94 & $(0.77,1.17)$ & \\
\hline Middle school vs College & 1.37 & $(0.97,2.02)$ & & 1.03 & $(0.84,1.27)$ & \\
\hline Primary school vs College & 2.17 & $(1.38,3.47)$ & & 0.89 & $(0.65,1.20)$ & \\
\hline Occupation & & & 0.319 & & & 0.016 \\
\hline Peasant vs Worker & 1.13 & $(0.48,2.29)$ & & 0.71 & $(0.38,1.23)$ & \\
\hline Officer vs Worker & 0.96 & $(0.7 \mathrm{I}, \mathrm{I} .28)$ & & 1.07 & $(0.90,1.28)$ & \\
\hline Service vs Worker & 1.21 & $(0.72,1.92)$ & & 0.83 & $(0.57,1.18)$ & \\
\hline Retired vs Worker & 1.39 & $(1.01,1.86)$ & & 0.83 & $(0.65,1.04)$ & \\
\hline Others vs Worker & 1.51 & $(0.7 \mathrm{I}, 2.87)$ & & 0.38 & $(0.16,0.75)$ & \\
\hline Labor intensity & & & 0.827 & & & 0.017 \\
\hline Moderate vs Light & 0.97 & $(0.79,1.19)$ & & 1.19 & $(1.04,1.36)$ & \\
\hline Heavy vs Light & 0.92 & $(0.68,1.22)$ & & 1.21 & $(1.01,1.46)$ & \\
\hline Mining exposure & & & $<0.001$ & & & $<0.001$ \\
\hline Yes vs No & 1.49 & $(1.23,1.80)$ & & 1.95 & $(I .72,2.21)$ & \\
\hline Mining exposure time (hours/week) & & & $<0.001$ & & & $<0.001$ \\
\hline $\mathrm{I}-40$ vs 0 & 1.16 & $(0.82,1.6 \mathrm{I})$ & & 1.94 & $(1.58,2.37)$ & \\
\hline $4 I-60$ vs 0 & 1.53 & $(1.23,1.91)$ & & 1.96 & $(1.70,2.28)$ & \\
\hline$>60$ vs 0 & 1.68 & $(1.26,2.21)$ & & 1.97 & $(1.62,2.40)$ & \\
\hline Dust exposure & & & 0.002 & & & $<0.001$ \\
\hline Yes vs No & 1.35 & $(1.12,1.64)$ & & 1.83 & $(\mathrm{I} .6 \mathrm{I}, 2.08)$ & \\
\hline Gas exposure & & & 0.003 & & & $<0.001$ \\
\hline Yes vs No & 1.34 & $(\mathrm{I} .1 \mathrm{I}, \mathrm{I} .6 \mathrm{I})$ & & 1.70 & $(1.50,1.92)$ & \\
\hline Smoking & & & 0.002 & & & $<0.001$ \\
\hline Occasionally vs Yes & 0.82 & $(0.55,1.17)$ & & 0.97 & $(0.78,1.20)$ & \\
\hline Refrained vs Yes & 1.19 & $(0.83,1.66)$ & & 0.91 & $(0.72,1.15)$ & \\
\hline Never vs Yes & 0.71 & $(0.58,0.87)$ & & 0.41 & $(0.36,0.48)$ & \\
\hline Drinking & & & $<0.001$ & & & $<0.001$ \\
\hline Occasionally vs Yes & 0.69 & $(0.55,0.87)$ & & 0.64 & $(0.55,0.73)$ & \\
\hline Refrained vs Yes & 0.67 & $(0.53,0.85)$ & & 0.35 & $(0.30,0.42)$ & \\
\hline Never vs Yes & 1.38 & $(0.85,2.12)$ & & 0.68 & $(0.47,0.96)$ & \\
\hline Smoke exposure & & & 0.016 & & & $<0.001$ \\
\hline Yes vs No & 1.38 & $(1.06,1.84)$ & & 1.69 & $(I .4 I, 2.04)$ & \\
\hline Disease history & & & 0.816 & & & 0.010 \\
\hline No vs Yes & 0.98 & $(0.8 \mathrm{I}, \mathrm{I} .18)$ & & 0.85 & $(0.75,0.96)$ & \\
\hline Hypertension & & & 0.502 & & & $<0.001$ \\
\hline No vs Yes & 0.93 & $(0.75,1.16)$ & & 0.76 & $(0.66,0.87)$ & \\
\hline Diabetes & & & 0.056 & & & 0.051 \\
\hline No vs Yes & 0.43 & $(0.21,1.02)$ & & 0.73 & $(0.53,1.02)$ & \\
\hline Tea consumption & & & $<0.001$ & & & $<0.001$ \\
\hline No vs Yes & 1.80 & $(1.33,2.50)$ & & 0.75 & $(0.64,0.87)$ & \\
\hline Fried food consumption & & & 0.103 & & & $<0.001$ \\
\hline Rarely or Never vs Yes & 0.84 & $(0.68,1.04)$ & & 0.79 & $(0.69,0.91)$ & \\
\hline Fresh fruit consumption & & & 0.143 & & & $<0.001$ \\
\hline Rarely or Never vs Yes & 1.15 & $(0.95,1.39)$ & & 1.45 & $(1.28,1.65)$ & \\
\hline Foreign residency & & & 0.017 & & & 0.483 \\
\hline No vs Yes & 0.60 & $(0.4 I, 0.9 I)$ & & 0.89 & $(0.66,1.23)$ & \\
\hline
\end{tabular}


A

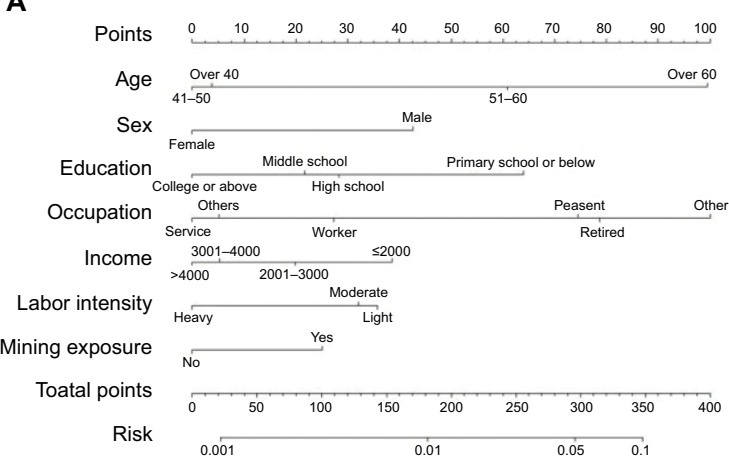

C

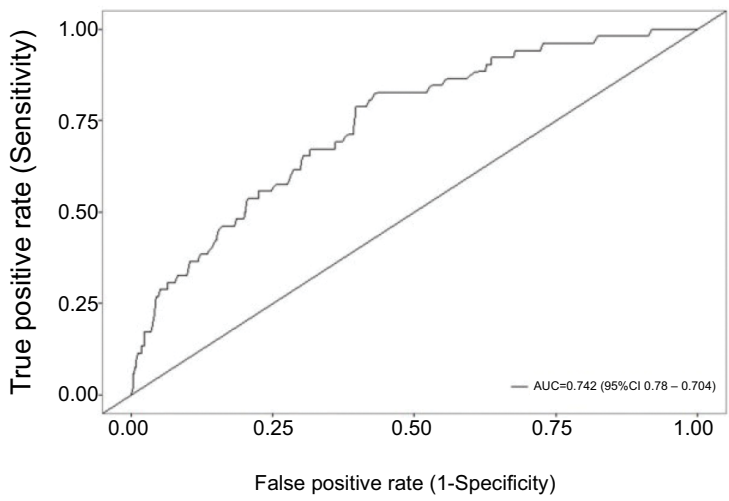

B

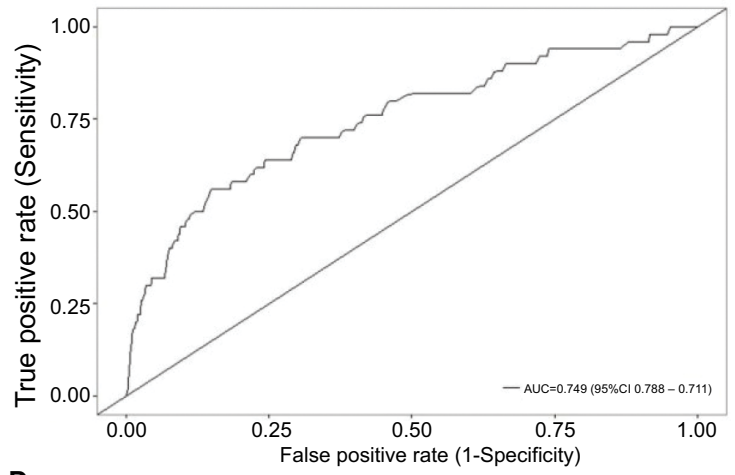

D

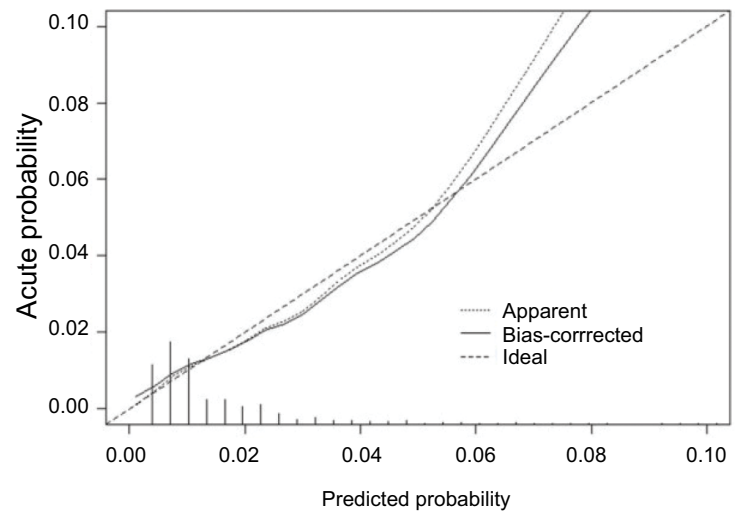

Figure $3 \mathrm{~A}$ nomogram for the prediction of ESCC and premalignant lesions.

Notes: Predictive nomogram of ESCC and premalignant lesions (A). ROC curve of this nomogram model (B). ROC curve of the validation of this nomogram model (C). Calibration curve of this nomogram model (D).

Abbreviations: ESCC, esophageal squamous cell carcinoma; ROC, receiver-operating characteristic.

Table 4 Sensitivity, specificity, and accuracy of patient selection strategy before endoscopy screening

\begin{tabular}{lllll}
\hline Lesions & Sensitivity (\%) & Specificity (\%) & Positive prediction value (\%) & Accuracy (\%) \\
\hline ESCC & 100.0 & 53.7 & 0.1 & 53.7 \\
Premalignant lesions & 72.4 & 54.0 & 2.0 & 54.2 \\
Precursor lesions & 57.3 & 54.7 & 7.2 & 54.5 \\
Reflux esophagitis & 60.6 & 56.2 & 19.9 & 56.9 \\
\hline
\end{tabular}

Abbreviation: ESCC, esophageal squamous cell carcinoma.

able that decreased immunity in older individuals resulted in a general increase in most diseases. ${ }^{18}$ Generally, people with lower income and who had received less education had a higher ESCC risk. Education and income were both associated with ESCC and premalignant lesions, which further supported the suggestion that ESCC is a poverty-related disease. ${ }^{19}$ Handan City has very considerable coal reserves, and many of our participants were involved in this industry. Hence, we included some occupational exposure factors in this study. Mining exposure was significantly associated with ESCC and premalignant lesions risk, and gas/dust exposures were risk factors for precancerous lesions/reflux esophagitis but not risk factors for ESCC/premalignant lesions. These results suggested that employees of the mining industry were part of the high-risk population for ESCC, which was in accordance with previous reports. ${ }^{20,21}$ Thus, we advocated that additional medical attention should be addressed in this population.

Nomograms as risk estimators have shown promising potential in clinical trial design and interpretation and have been widely adopted in prognostic models. ${ }^{22-24}$ However, their application in primary health screening, such as cancer screening programs, is rare. ${ }^{25,26}$ In this study, we established a nomogram-based method to select the eligible population for endoscopic screening based on different risk factors. Through such a potential patient selection strategy, we could exclude $60 \%$ of people before endoscopic screening without missing 
even one ESCC case. To our knowledge, this is the first study providing a nomogram to predict individual ESCC risk. These results suggest that the nomogram is a very powerful tool in individual risk assessment, one that could be used in ESCC screening and, most likely, in other primary health screening programs, as well.

There are also some limitations in our nomogram-based model. First, all nomograms were based on a retrospective single-center dataset, which would weaken the confidence of our risk prediction model and shrink its application range. Second, we used only demographic and lifestyle information to construct the model and did not include any biochemistry or hematology tests. Nomograms based on a dataset with more dimensions may provide a more accurate prediction, at a much greater cost. However, the aim of this study was not to deliver a perfect predictive tool but to develop a proper strategy for selecting an eligible population for endoscopic screening that was better than currently available approaches. For ESCC, a disease mainly occurring in developing areas, our model would be much available and affordable.

In conclusion, we provided a ready-to-use preclinical tool with the potential to select eligible people with high ESCC risk for endoscopy screening. This tool is not ideal but is very useful, and in the future, a multicentered prospective study with a larger population would provide a more reliable patient selection strategy.

\section{Data availability}

Additional supporting information may be found in the online version of this article.

\section{Acknowledgments}

This work was fully supported by National Natural Science Foundation of People's Republic of China (grant nos. 81302160 and 81272447), the Beijing Natural Science Foundation Program, the Research Foundation of Beijing Friendship Hospital, Capital Medical University (grant no.yyqdkt2017-15) and the Scientific Research Key Program of the Beijing Municipal Commission of Education (grant no. KZ201410025024).

We would like to deeply appreciate the core members of the North China Esophageal Cancer Screening (NCECS) Study Group, whose names were not able to be fully displayed in the author list according to GPP3 guidelines. Their dedicated endoscopy operations were the most important intellectual contributions to this study, which could never be ignored.
Core member of the NCECS Study Group: Xuan Liu, ${ }^{1}$ Qiaozhi Zhou, ${ }^{1}$ Yue Jiao, ${ }^{1}$ Ying Meng, ${ }^{1}$ Ye Zong, ${ }^{1}$ Qinggang Wang, ${ }^{1}$ Yinglin Niu, ${ }^{1}$ Hongmei Li, ${ }^{1}$ Li Yu, ${ }^{1}$ Haiying Zhao, ${ }^{1}$ Wenyan Li, ${ }^{1}$ Xun Yang, ${ }^{1}$ Li Zhang, ${ }^{1}$ Fandong Meng, ${ }^{1}$ Haiyi $\mathrm{Hu},{ }^{1}$ Yanhua Zhou, ${ }^{1}$ Shuxia Yu, ${ }^{2}$ Baohong Xu, ${ }^{3}$ Jianyu Hao, ${ }^{4}$ Aimin Wang, ${ }^{5}$ Zhen He, ${ }^{1}$ Chuntao Liu, ${ }^{1}$ Jian Wei, ${ }^{1}$ Yue Tian, ${ }^{1}$ Pei Zhang, ${ }^{1}$ Zhonglin $\mathrm{Yu}^{1}$

${ }^{1}$ Department of Gastroenterology, Beijing Friendship Hospital, Capital Medical University, Beijing 100050, People's Republic of China; ${ }^{2}$ Department of Gastroenterology, Daxing Hospital, Beijing 102600, People's Republic of China; ${ }^{3}$ Department of Gastroenterology, Luhe Hospital, Beijing 101100, People's Republic of China; ${ }^{4}$ Department of Gastroenterology, Beijing Chaoyang Hospital, Beijing 100020, People's Republic of China; ${ }^{5}$ Department of Gastroenterology, The 252nd Hospital of PLA, Baoding 071000, People's Republic of China.

\section{Author contributions}

JX and LM carried out the main analysis. JX, LM, S. Zhu, and $\mathrm{S}$. Zhang conceived and designed the study. HZ and JW coordinated the cooperation between the National Clinical Research Center for Digestive Disease and the local community. ZZ and HL helped to perform statistical analysis. XS and her group performed the pathological diagnosis. QG, SW, and YZ helped to collect data. AW helped to analyze data. LM, JX, ZZ, HL, and S. Zhang drafted the manuscript. WL and FL instructed those conducting the endoscopy examinations. Y. Wu, PL, MJ, and Y. Wang monitored the endoscopy examinations. All other coauthors and the NCECS Study Group performed endoscopy examinations. All authors contributed to data analysis, drafting and revising the article, gave final approval of the version to be published, and agree to be accountable for all aspects of the work. S. Zhang is the guarantor of the article.

\section{Disclosure}

The authors report no conflicts of interest in this work.

\section{References}

1. Torre LA, Bray F, Siegel RL, Ferlay J, Lortet-Tieulent J, Jemal A. Global cancer statistics, 2012. CA Cancer J Clin. 2015;65(2):87-108.

2. Siegel RL, Miller KD, Jemal A. Cancer statistics, 2015.CA Cancer J Clin. 2015;65(1):5-29.

3. Chen W, Zheng R, Baade PD, et al. Cancer statistics in China, 2015. CA Cancer J Clin. 2016;66(2):115-132.

4. Yu S, Zhang W, Ni W, et al. Nomogram and recursive partitioning analysis to predict overall survival in patients with stage IIB-III thoracic esophageal squamous cell carcinoma after esophagectomy. Oncotarget. 2016;7(34):55211-55221.

5. Luo LN, He LJ, Gao XY, et al. Evaluation of preoperative staging for esophageal squamous cell carcinoma. World $J$ Gastroenterol. 2016;22(29):6683-6689. 
6. Kumar V, Abbas A, Fausto N, Aster J. Pathologic Basis of Disease. Robbins and Cotran, editors. Philadelphia: Saunders Elsevier; 2010.

7. Morimoto M, Nishiyama K, Nakamura S, et al. Significance of endoscopic screening and endoscopic resection for esophageal cancer in patients with hypopharyngeal cancer. Jpn J Clin Oncol. 2010;40(10):938-943.

8. Chaber-Ciopinska A, Kiprian D, Kawecki A, Kaminski MF. Surveillance of patients at high-risk of squamous cell esophageal cancer. Best Pract Res Clin Gastroenterol. 2016;30(6):893-900.

9. PDQ. Screening and Prevention Editorial B. Esophageal Cancer Screening (PDQ(R)): Health Professional Version. PDQ Cancer Information Summaries. Bethesda (MD): National Cancer Institute; 2016.

10. Hu WS, Liu ZJ, Zhang JB, et al. Risk patterns of subsequent primary cancers following esophagectomy in early-stage thoracic esophageal squamous cell cancer patients. Tumori. 2015;101(3):328-333.

11. Lucenteforte E, Garavello W, Bosetti C, et al. Diet diversity and the risk of squamous cell esophageal cancer. Int $J$ Cancer. 2008;123(10):2397-2400.

12. Wei WQ, Chen ZF, He YT, et al. Long-term follow-up of a community assignment, one-time endoscopic screening study of esophageal cancer in China. J Clin Oncol. 2015;33(17):1951-1957.

13. Yokoyama A, Oda J, Iriguchi Y, et al. A health-risk appraisal model and endoscopic mass screening for esophageal cancer in Japanese men. Dis Esophagus.2013;26(2):148-153.

14. Domper Arnal MJ, Ferrández Arenas Á, Lanas Arbeloa Á. Esophageal cancer: risk factors, screening and endoscopic treatment in Western and Eastern countries. World J Gastroenterol. 2015;21(26):7933-7943.

15. Wani S, Das A, Rastogi A, et al. Endoscopic ultrasonography in esophageal cancer leads to improved survival rates: results from a populationbased study. Cancer. 2015;121(2):194-201.

16. Gupta N, Bansal A, Wani SB, Gaddam S, Rastogi A, Sharma P. Endoscopy for upper GI cancer screening in the general population: a costutility analysis. Gastrointest Endosc. 2011;74(3):610-624.
17. Yang J, Wei WQ, Niu J, et al. Estimating the costs of esophageal cancer screening, early diagnosis and treatment in three high risk areas in China. Asian Pac J Cancer Prev. 2011;12(5):1245-1250.

18. Yaqoob P. Ageing alters the impact of nutrition on immune function. Proc Nutr Soc. 2017;76(3):347-351.

19. Lagergren J, Andersson G, Talbäck M, et al. Marital status, education, and income in relation to the risk of esophageal and gastric cancer by histological type and site. Cancer. 2016;122(2):207-212.

20. Santibañez M, Vioque J, Alguacil J, et al. Occupational exposures and risk of oesophageal cancer by histological type: a case-control study in eastern Spain. Occup Environ Med. 2008;65(11):774-781.

21. Vizcaino AP, Parkin DM, Skinner ME. Risk factors associated with oesophageal cancer in Bulawayo, Zimbabwe. Br J Cancer. 1995;72(3):769-773.

22. Kim SK, Chai YJ, Park I, et al. Nomogram for predicting central node metastasis in papillary thyroid carcinoma. J Surg Oncol. 2017;115(3):266-272.

23. Zhang J, Li X, Huang R, et al. A nomogram to predict the probability of axillary lymph node metastasis in female patients with breast cancer in China: a nationwide, multicenter, 10-year epidemiological study. Oncotarget. 2017;8(21):35311-35325.

24. Zhou ML, Wang L, Wang JZ, et al. Validation of the Memorial Sloan Kettering Cancer Center nomogram to predict disease-specific survival in a Chinese gastric cancer population receiving postoperative chemoradiotherapy after an R0 resection. Oncotarget. 2016;7(40):64757-64765.

25. Bass JL, Bhatia A, Boas FE, Sansary J, Rauch D. Validation of a body mass index nomogram for children as an obesity screening tool in young children. Clin Pediatr. 2006;45(8):718-724.

26. Rozendaal L, Groenink M, Naeff MS, et al. Marfan syndrome in children and adolescents: an adjusted nomogram for screening aortic root dilatation. Heart. 1998;79(1):69-72. 


\section{Supplementary material}

Table SI Univariate analysis of esophageal lesions risk factors

\begin{tabular}{|c|c|c|c|c|c|c|c|c|c|}
\hline & \multicolumn{3}{|c|}{ Precursor lesions } & \multicolumn{3}{|c|}{$\begin{array}{l}\text { Premalignant/malignant } \\
\text { lesions }\end{array}$} & \multicolumn{3}{|c|}{ Reflux esophagitis } \\
\hline & OR & $95 \% \mathrm{Cl}$ & $P$ & OR & $95 \% \mathrm{Cl}$ & $P$ & OR & $95 \% \mathrm{Cl}$ & $P$ \\
\hline Age (years) & & & $<0.001$ & & & $<0.001$ & & & 0.002 \\
\hline $4 \mathrm{I}-50$ vs $\leq 40$ & 1.59 & $(0.98,2.78)$ & & 1.06 & $(0.38,4.44)$ & & 1.24 & $(0.94,1.66)$ & \\
\hline $5 \mathrm{I}-60$ vs $\leq 40$ & 2.42 & $(1.48,4.23)$ & & 3.76 & $(1.38,15.48)$ & & 1.52 & $(1.14,2.05)$ & \\
\hline$>60$ vs $\leq 40$ & 3.36 & $(1.80,6.46)$ & & 10.87 & $(3.61,46.90)$ & & 1.56 & $(1.03,2.34)$ & \\
\hline Gender & & & $<0.001$ & & & 0.009 & & & $<0.001$ \\
\hline Female vs Male & 0.62 & $(0.50,0.79)$ & & 0.54 & $(0.32,0.86)$ & & 0.23 & $(0.19,0.28)$ & \\
\hline Race & & & 0.614 & & & 0.174 & & & 0.834 \\
\hline Others vs Han & 0.71 & $(0.11,2.29)$ & & 3.21 & $(0.52,10.58)$ & & 1.09 & $(0.47,2.20)$ & \\
\hline Married & & & 0.273 & & & 0.986 & & & 0.344 \\
\hline Others vs Married & 1.59 & $(0.66,3.25)$ & & 1.02 & $(0.06,4.67)$ & & 0.72 & $(0.34,1.38)$ & \\
\hline Education & & & 0.002 & & & $<0.001$ & & & 0.489 \\
\hline High school vs College & 1.69 & $(1.18,2.49)$ & & 1.15 & $(0.59,2.46)$ & & 0.94 & $(0.77,1.17)$ & \\
\hline Middle school vs College & 1.37 & $(0.97,2.02)$ & & 0.91 & $(0.47,1.94)$ & & 1.03 & $(0.84,1.27)$ & \\
\hline Primary school vs College & 2.17 & $(1.38,3.47)$ & & 3.37 & $(1.58,7.60)$ & & 0.89 & $(0.65,1.20)$ & \\
\hline Occupation & & & 0.319 & & & $<0.001$ & & & 0.016 \\
\hline Peasant vs Worker & 1.13 & $(0.48,2.29)$ & & 3.15 & $(0.76,8.77)$ & & 0.71 & $(0.38,1.23)$ & \\
\hline Officer vs Worker & 0.96 & $(0.7 \mathrm{I}, \mathrm{I.28})$ & & 2.34 & $(1.37,3.86)$ & & 1.07 & $(0.90,1.28)$ & \\
\hline Service vs Worker & 1.21 & $(0.72,1.92)$ & & 0.44 & $(0.02,2.01)$ & & 0.83 & $(0.57,1.18)$ & \\
\hline Retired vs Worker & 1.39 & $(1.01,1.86)$ & & 4.76 & $(2.92,7.61)$ & & 0.83 & $(0.65,1.04)$ & \\
\hline Others vs Worker & 1.51 & $(0.7 \mathrm{I}, 2.87)$ & & 1.09 & $(0.06,5.07)$ & & 0.38 & $(0.16,0.75)$ & \\
\hline Labor intensity & & & 0.827 & & & 0.006 & & & 0.017 \\
\hline Moderate vs Light & 0.97 & $(0.79,1.19)$ & & 0.59 & $(0.37,0.91)$ & & 1.19 & $(1.04,1.36)$ & \\
\hline Heavy vs Light & 0.92 & $(0.68,1.22)$ & & 0.39 & $(0.16,0.80)$ & & 1.21 & $(1.01,1.46)$ & \\
\hline Income(¥) & & & 0.119 & & & 0.008 & & & 0.232 \\
\hline $2,00 \mathrm{I}-3,000$ vs $\leq 2,000$ & 0.79 & $(0.62,1.01)$ & & 0.52 & $(0.32,0.84)$ & & 0.98 & $(0.83,1.16)$ & \\
\hline $3,00 \mathrm{I}-4,000$ vs $\leq 2,000$ & 0.75 & $(0.57,0.98)$ & & 0.44 & $(0.24,0.76)$ & & 1.15 & $(0.96,1.38)$ & \\
\hline$>4,000$ vs $\leq 2,000$ & 0.75 & $(0.56,0.99)$ & & 0.47 & $(0.25,0.84)$ & & 1.01 & $(0.83,1.22)$ & \\
\hline Mining exposure & & & $<0.001$ & & & 0.033 & & & $<0.001$ \\
\hline Yes vs No & 1.49 & $(1.23,1.80)$ & & 1.53 & $(1.04,2.29)$ & & 1.95 & $(1.72,2.21)$ & \\
\hline Mining exposure time (hours/week) & & & $<0.001$ & & & 0.122 & & & $<0.001$ \\
\hline $1-40$ vs 0 & 1.16 & $(0.82, I .6 I)$ & & 1.39 & $(0.68,2.62)$ & & 1.94 & $(1.58,2.37)$ & \\
\hline $4 I-60$ vs 0 & 1.53 & $(1.23,1.91)$ & & 1.65 & $(1.04,2.61)$ & & 1.96 & $(1.70,2.28)$ & \\
\hline$>60$ vs 0 & 1.68 & $(1.26,2.21)$ & & 1.67 & $(0.89,2.95)$ & & 1.97 & $(1.62,2.40)$ & \\
\hline Dust exposure & & & 0.002 & & & 0.299 & & & $<0.001$ \\
\hline Yes vs No & 1.35 & $(1.12,1.64)$ & & 1.23 & $(0.83,1.84)$ & & 1.83 & $(\mathrm{I} .6 \mathrm{I}, 2.08)$ & \\
\hline Gas exposure & & & 0.003 & & & 0.610 & & & $<0.001$ \\
\hline Yes vs No & 1.34 & $(I . I I, I .6 I)$ & & 0.90 & $(0.60,1.33)$ & & 1.70 & $(1.50,1.92)$ & \\
\hline Smoking & & & 0.002 & & & 0.150 & & & $<0.001$ \\
\hline Occasionally vs Yes & 0.82 & $(0.55,1.17)$ & & 1.00 & $(0.43,2.03)$ & & 0.97 & $(0.78,1.20)$ & \\
\hline Refrained vs Yes & 1.19 & $(0.83,1.66)$ & & 1.90 & $(0.97,3.48)$ & & 0.91 & $(0.72,1.15)$ & \\
\hline Never vs Yes & 0.71 & $(0.58,0.87)$ & & 0.86 & $(0.55,1.33)$ & & $0.4 I$ & $(0.36,0.48)$ & \\
\hline Drinking & & & $<0.001$ & & & $0.45 I$ & & & $<0.001$ \\
\hline Occasionally vs Yes & 0.69 & $(0.55,0.87)$ & & 1.08 & $(0.66,1.74)$ & & 0.64 & $(0.55,0.73)$ & \\
\hline Refrained vs Yes & 0.67 & $(0.53,0.85)$ & & 0.93 & $(0.56,1.54)$ & & 0.35 & $(0.30,0.42)$ & \\
\hline Never vs Yes & 1.38 & $(0.85,2.12)$ & & 2.06 & $(0.77,4.62)$ & & 0.68 & $(0.47,0.96)$ & \\
\hline Smoking exposure & & & 0.016 & & & 0.333 & & & $<0.001$ \\
\hline Yes vs No & 1.38 & $(1.06,1.84)$ & & 0.79 & $(0.50,1.30)$ & & 1.69 & $(I .4 I, 2.04)$ & \\
\hline Smoking time $>15$ minutes & & & 0.181 & & & 0.924 & & & $<0.001$ \\
\hline Yes vs No & 0.87 & $(0.70,1.07)$ & & 0.98 & $(0.63,1.48)$ & & 0.70 & $(0.6 \mathrm{I}, 0.8 \mathrm{I})$ & \\
\hline
\end{tabular}


Table SI (Continued)

\begin{tabular}{|c|c|c|c|c|c|c|c|c|c|}
\hline & \multicolumn{3}{|c|}{ Precursor lesions } & \multicolumn{3}{|c|}{$\begin{array}{l}\text { Premalignant/malignant } \\
\text { lesions }\end{array}$} & \multicolumn{3}{|c|}{ Reflux esophagitis } \\
\hline & OR & $95 \% \mathrm{Cl}$ & $P$ & OR & $95 \% \mathrm{Cl}$ & $P$ & OR & $95 \% \mathrm{Cl}$ & $\boldsymbol{P}$ \\
\hline Disease history & & & 0.816 & & & 0.188 & & & 0.010 \\
\hline No vs Yes & 0.98 & $(0.81,1.18)$ & & 0.77 & $(0.52,1.14)$ & & 0.85 & $(0.75,0.96)$ & \\
\hline Heart disease & & & 0.207 & & & 0.807 & & & 0.840 \\
\hline No vs Yes & 0.82 & $(0.6 \mathrm{I}, \mathrm{I} .12)$ & & 0.92 & $(0.50,1.89)$ & & 1.02 & $(0.83,1.27)$ & \\
\hline Diabetes & & & 0.264 & & & 0.056 & & & 0.061 \\
\hline No vs Yes & 1.41 & $(0.79,2.87)$ & & 0.43 & $(0.21,1.02)$ & & 0.73 & $(0.53,1.02)$ & \\
\hline Hypertension & & & 0.502 & & & 0.033 & & & $<0.001$ \\
\hline No vs Yes & 0.93 & $(0.75,1.16)$ & & 0.63 & $(0.42,0.96)$ & & 0.76 & $(0.66,0.87)$ & \\
\hline Digestive disease & & & 0.816 & & & 0.292 & & & 0.225 \\
\hline No vs Yes & 1.03 & $(0.79,1.36)$ & & 0.76 & $(0.47,1.29)$ & & 1.12 & $(0.94,1.34)$ & \\
\hline Respiratory disease & & & 0.536 & & & 0.342 & & & 0.079 \\
\hline No vs Yes & 0.90 & $(0.66,1.26)$ & & 0.74 & $(0.42,1.42)$ & & 0.83 & $(0.68,1.02)$ & \\
\hline Tumor history & & & 0.827 & & & 0.879 & & & 0.821 \\
\hline No vs Yes & 0.98 & $(0.80,1.20)$ & & 0.97 & $(0.64,1.49)$ & & 1.02 & $(0.89,1.16)$ & \\
\hline Other disease history & & & 0.507 & & & 0.831 & & & 0.664 \\
\hline No vs Yes & 0.91 & $(0.7 \mathrm{I}, \mathrm{I} .20)$ & & & & & 0.96 & $(0.8 \mathrm{I}, \mathrm{I.15})$ & \\
\hline Tea consumption & & & $<0.001$ & & & 0.038 & & & $<0.001$ \\
\hline No vs Yes & 1.80 & $(1.33,2.50)$ & & 0.60 & $(0.39,0.97)$ & & 0.75 & $(0.64,0.87)$ & \\
\hline Eating postures & & & 0.644 & & & 0.069 & & & 0.463 \\
\hline Sit vs Squat & 0.91 & $(0.47,2.04)$ & & 0.80 & $(0.25,4.87)$ & & 1.34 & $(0.80,2.40)$ & \\
\hline Stand vs Squat & 1.93 & $(0.27,8.65)$ & & 0.73 & $(0.88,68.48)$ & & 0.87 & $(0.13,3.47)$ & \\
\hline High temperature food intake & & & 0.095 & & & 0.561 & & & 0.511 \\
\hline No vs Yes & 1.18 & $(0.97,1.43)$ & & 1.13 & $(0.76,1.69)$ & & 0.96 & $(0.85,1.09)$ & \\
\hline Fast eating & & & 0.238 & & & 0.631 & & & 0.087 \\
\hline No vs Yes & 1.12 & $(0.93,1.35)$ & & 0.91 & $(0.6 \mathrm{I}, \mathrm{I} .34)$ & & 0.90 & $(0.79,1.02)$ & \\
\hline Salted food consumption & & & 0.449 & & & 0.654 & & & 0.544 \\
\hline Rarely or Never vs Yes & 0.93 & $(0.77,1.13)$ & & 1.10 & $(0.73,1.67)$ & & 0.96 & $(0.85,1.09)$ & \\
\hline Fried food consumption & & & 0.103 & & & 0.270 & & & $<0.001$ \\
\hline Rarely or Never vs Yes & 0.84 & $(0.68,1.04)$ & & 0.78 & $(0.52,1.22)$ & & 0.79 & $(0.69,0.91)$ & \\
\hline Chilli food consumption & & & 0.295 & & & 0.187 & & & 0.724 \\
\hline Rarely or Never vs Yes & 1.12 & $(0.91,1.40)$ & & 1.36 & $(0.86,2.24)$ & & 0.98 & $(0.85,1.12)$ & \\
\hline Moldy food consumption & & & 0.751 & & & 0.83 & & & 0.916 \\
\hline No vs Yes & 1.20 & $(0.44,4.94)$ & & 0.80 & $(0.17,14.18)$ & & 1.04 & $(0.54,2.26)$ & \\
\hline Leek food consumption & & & 0.339 & & & 0.535 & & & 0.702 \\
\hline Rarely or Never vs Yes & 0.88 & $(0.66,1.15)$ & & & & & 0.97 & $(0.81,1.15)$ & \\
\hline Bean food consumption & & & 0.177 & & & $0.70 \mathrm{I}$ & & & 0.334 \\
\hline Rarely or Never vs Yes & 0.83 & $(0.63,1.08)$ & & 0.90 & $(0.50,1.5 \mathrm{I})$ & & 0.92 & $(0.77,1.09)$ & \\
\hline Meat/egg/milk consumption & & & 0.359 & & & 0.223 & & & 0.115 \\
\hline Rarely or Never vs Yes & 0.83 & $(0.54,1.22)$ & & 0.56 & $(0.17,1.35)$ & & 0.81 & $(0.62,1.05)$ & \\
\hline Dry food consumption & & & 0.133 & & & 0.198 & & & 0.404 \\
\hline Rarely or Never vs Yes & 1.17 & $(0.95,1.43)$ & & 1.32 & $(0.87,2.05)$ & & 1.06 & $(0.93,1.20)$ & \\
\hline Maize consumption & & & 0.177 & & & 0.075 & & & 0.530 \\
\hline Rarely or Never vs Yes & 1.14 & $(0.94,1.38)$ & & $\mathrm{I} .43$ & $(0.96,2.12)$ & & 1.04 & $(0.92,1.18)$ & \\
\hline Fresh vegetable consumption & & & 0.036 & & & 0.316 & & & 0.213 \\
\hline Rarely or Never vs Yes & $10^{-6}$ & $\left(10^{-38}, 0.22\right)$ & & $10^{-6}$ & $\left(10^{-59}, 526.04\right)$ & & 0.50 & $(0.12, I .4 I)$ & \\
\hline Fresh fruit consumption & & & 0.143 & & & 0.090 & & & $<0.001$ \\
\hline Rarely or Never vs Yes & 1.15 & $(0.95,1.39)$ & & $\mathrm{I} .40$ & $(0.95,2.10)$ & & 1.45 & $(1.28,1.65)$ & \\
\hline Sauerkraut consumption & & & 0.288 & & & 0.667 & & & 0.656 \\
\hline No vs Yes & 1.16 & $(0.88,1.56)$ & & 0.89 & $(0.53,1.57)$ & & 0.96 & $(0.81,1.45)$ & \\
\hline Water source & & & 0.839 & & & 0.481 & & & 0.316 \\
\hline Natural vs Others & 1.04 & $(0.67,1.55)$ & & 1.34 & $(0.56,2.70)$ & & 1.15 & $(0.87,1.49)$ & \\
\hline Foreign residency & & & 0.017 & & & 0.137 & & & 0.483 \\
\hline No vs Yes & 0.60 & $(0.4 I, 0.9 I)$ & & 0.53 & $(0.26,1.26)$ & & 0.89 & $(0.66,1.23)$ & \\
\hline
\end{tabular}




\section{Publish your work in this journal}

Cancer Management and Research is an international, peer-reviewed open access journal focusing on cancer research and the optimal use of preventative and integrated treatment interventions to achieve improved outcomes, enhanced survival and quality of life for the cancer patient. The manuscript management system is completely online and includes a very quick and fair peer-review system, which is all easy to use. Visit http://www.dovepress.com/testimonials.php to read real quotes from published authors.

Submit your manuscript here: https://www.dovepress.com/cancer-management-and-research-journal 